\title{
A Recently Discovered Maize Polerovirus Causes Leaf Reddening Symptoms in Several Maize Genotypes and is Transmitted by Both the Corn Leaf Aphid (Rhopalosiphum maidis) and the Bird Cherry-Oat Aphid (Rhopalosiphum padi)
}

\author{
Lucy R. Stewart ${ }^{1,2, \dagger}$, Jane Todd ${ }^{1}$, Kristen Willie ${ }^{1}$, Deogracious Massawe ${ }^{2}$, and Nitika Khatri ${ }^{2}$ \\ ${ }^{1}$ USDA-ARS Corn, Soybean and Wheat Quality Research Unit, Wooster, OH 44691 \\ ${ }^{2}$ Plant Pathology Department, The Ohio State University, Wooster, OH 44691
}

\begin{abstract}
A maize-infecting polerovirus variously named maize yellow dwarf virus RMV2 (MYDV-RMV2) and maize yellow mosaic virus (MaYMV) has been discovered and previously described in East Africa, Asia, and South America. It was identified in virus surveys in these locations instigated by outbreaks of maize lethal necrosis (MLN), known to be caused by coinfections of unrelated maize chlorotic mottle virus (MCMV) and any of several maize-infecting potyviruses, and was often found in coinfections with MLN viruses. Although sequenced in many locations globally and named for symptoms of related or coin-

symptoms in single infections, has not been reported until now. We report isolation from other viruses and leaf tip reddening symptoms in several maize genotypes, along with transmission by two aphids, Rhopalosiphum padi and Rhopalosiphum maidis. This is important information distinguishing this virus and demonstrating that in single infections it causes symptoms distinct from those of potyviruses or MCMV in maize, and identification of vectors provides an important framework for determination of potential disease impact and management.
\end{abstract} fecting viruses, and with an infectious clone reported that experimentally infects Nicotiana benthamiana, rudimentary biological characterization of MaYMV in maize, including insect vector(s) and
Keywords: polerovirus, maize yellow mosaic virus, aphid transmission, maize yellow dwarf virus RMV2
A maize (Zea mays L.)-associated polerovirus has been discovered and described by us and others in Africa (Guadie et al. 2018; Mahuku et al. 2015; Massawe et al. 2018; Palanga et al. 2017), Asia (Chen et al. 2016; Wang et al. 2016), and South America (Bernreiter et al. 2017; Gonçalves et al. 2017) in conjunction with surveys for maize viruses in locations with maize lethal necrosis (MLN) emergence. Most of these studies were conducted using deep sequencing and identified sequences of known MLN viruses, as well as sequences of this polerovirus. No symptoms have previously been defined for single infection of this virus. However, it has been given various symptom-descriptive names, including maize yellow dwarf virus-RMV2 (MYDV-RMV2) (Wang et al. 2016) and MYDV-like (Massawe et al. 2018) for the most similar virus at the time of discovery, and maize yellow mosaic virus (MaYMV) for symptoms observed in plants infected with this virus but also coinfected with the mosaic-causing potyvirus sugarcane mosaic virus (SCMV)

${ }^{\dagger}$ Corresponding author: L. R. Stewart; lucy.stewart@usda.gov

Mention of trade names in this publication is solely for the purpose of providing specific information and does not imply recommendation or endorsement by the U.S. Department of Agriculture. USDA is an equal opportunity provider and employer.

Funding: This research was supported by USDA-ARS base funding (project no. 5082-22000-001-00D).

The author(s) declare no conflict of interest.

Accepted for publication 13 December 2019.

This article is in the public domain and not copyrightable. It may be freely reprinted with customary crediting of the source. The American Phytopathological Society, 2020.
(Chen et al. 2016). In East Africa, this polerovirus is highly prevalent, with limited sequence diversity among East African isolates or between East African isolates and Asian isolates (Massawe et al. 2018). Although prevalent and found in several surveys for MLN viruses, the biology of MaYMV, including its vector(s), symptoms, and contribution to disease, if any, have yet to be elucidated. Even though an infectious clone for MaYMV was reported, with apparently asymptomatic infection of the dicotyledonous model plant for virology, Nicotiana benthamiana, no subsequent transmission to maize was successful (Chen et al. 2016).

Other members of the genus Polerovirus include the type species for which the genus is named, Potato leafroll virus, and monocotinfecting virus species including Cereal yellow dwarf virus RPS and RPV and Sugarcane yellow leaf virus. Most characterized poleroviruses have been demonstrated to be phloem-limited and aphidtransmitted (save for a recent report of atypical whitefly transmission of an emergent pepper polerovirus [Ghosh et al. 2019]). Typically, these viruses have low titers in infected plants. The symptoms of poleroviruses may include leaf tip reddening or yellowing as well as possible changes in leaf shape or stunting, and sometimes no readily observed symptoms at all, while mosaic is not a typical manifestation of polerovirus infection (Grisham et al. 2010; Nega 2014). Based on this information from other poleroviruses, we hypothesized that MaYMV would be similar to those of other poleroviruses in monocots rather than mosaic such as maize chlorotic mottle virus (MCMV) or SCMV. We further hypothesized that MaYMV was likely transmitted by aphids, prospective vector species that are ubiquitous globally and in East Africa and are likely the same species that transmit SCMV and other potyviruses in locations where MaYMV has been identified. Unlike MCMV and SCMV, MaYMV is not mechanically transmissible by rub-inoculation, nor were reported infectious clones successfully transmitted to maize (Chen et al. 2016). Although aphid vectors were already suspected based on the transmission of other poleroviruses, no insect vectors have previously 
been defined for MaYMV. Therefore, MaYMV had yet to be studied in maize without the confounding effects of coinfection.

To test symptoms and transmission of MaYMV in maize in the absence of coinfecting viruses, aphids identified as Rhopalosiphum maidis were field-collected from maize in Morogoro, Tanzania, where SCMV and MaYMV are common but MCMV is more rare (Massawe and Stewart, unpublished data based on serological assays where available, and deep sequencing with RT-PCR confirmation). To separate MaYMV from the only other aphid-transmitted viruses detected in Tanzanian maize so far, nonpersistently aphidtransmitted potyviruses including SCMV, and from viruses not transmitted by aphids such as MCMV, field-collected aphids were placed on seedlings of locally available maize cultivar PAN4M-19 for serial transmission to healthy plants. Test seedlings were grown in a greenhouse in disinfested forest soil previously cooked for $8 \mathrm{~h}$ in a lidded pot. Field-collected aphids were placed on a first set of maize seedlings and allowed to transmit virus and feed for $5 \mathrm{~min}$. Aphids were then removed and transferred to a new set of healthy plants to feed for $15 \mathrm{~min}$, then removed to a third set of healthy plants to feed for $20 \mathrm{~min}$, and then to a fourth set to feed for $30 \mathrm{~min}$ in an effort to flush nonpersistently transmitted virus(es) (SCMV or other potyviruses) they might carry. Then, aphids were removed to a new set of test maize seedlings and further allowed to transmit and feed for 2 days. Insect transmission experiments were conducted in $150 \times 150$ mesh, $160 \mu \mathrm{m}$ aperture nylon BugDorm cages (MegaView Science Co., Ltd., Taiwan). Aphids were then removed from test plants by fumigation with chloropyrifos (Pyrinex; Adama, Beer Sheva, Israel), and plants were allowed to mature. At 12 days post-aphid infestation (dpi), plants were tested for SCMV, MCMV, and MaYMV using diagnostic primers DM03/DM04 for MaYMV (Massawe et al. 2018), DM60/DM66 for MCMV, and DM74/DM75 for SCMV (Table 1). RNA was extracted from maize plants using Directzol RNA MiniPrep kits (ZymoResearch, Irvine, CA), and one-step RT-PCR was carried out using Superscript III reverse transcription (Invitrogen, Carlsbad, CA) and GoTaq polymerase (Promega, Madison, WI). After a $40 \mathrm{~min}, 52^{\circ} \mathrm{C}$ reverse transcription and $2 \mathrm{~min}, 94^{\circ} \mathrm{C}$ denaturation, amplification was performed with 32 cycles of $94^{\circ} \mathrm{C}$ for $15 \mathrm{~s}$, $30 \mathrm{~s}$ annealing $\left(60^{\circ} \mathrm{C}\right.$ for MaYMV, $62.5^{\circ} \mathrm{C}$ for SCMV, and $62^{\circ} \mathrm{C}$ for MCMV), and $72^{\circ} \mathrm{C}$ extension for 1 min followed by a final 5 min extension at $72^{\circ} \mathrm{C}$. Out of 32 plants screened, MCMV was not detected in any, and SCMV was detected in one plant in which MaYMV was also detected. MaYMV was detected in 23 of 32 test plants. Plants testing positive for only MaYMV were allowed to mature for $28 \mathrm{dpi}$, when leaves were collected from each plant and given corresponding sample numbers (S1 to S23). Nine additional MaYMV-infected plants were recovered using the same methodology using aphids collected in Arusha, Tanzania, and corresponding samples were numbered S24 to S32 (Table 2). Leaves were lyophilized and shipped to the USDA-ARS Corn, Soybean and Wheat Quality Research unit laboratories at Wooster, Ohio, for further experimentation.

In Ohio, a subset of lyophilized samples was ground in $0.01 \mathrm{M} \mathrm{pH} 7$ potassium phosphate buffer and screened using generic potyvirus immunostrips (Agdia, Inc., Elkhart, IN) to remove samples with potyvirus coinfections that were not detected by SCMV RT-PCR (2/7 tested samples were potyvirus-positive). Since barley yellow dwarf virus (BYDV) has been detected in a few Rwandan maize samples (Asiimwe et al. 2020) and has similar transmission mode and properties expected for poleroviruses, RNA samples from lyophilized tissue used for subsequent experiments and RNA from a subset of plants with MaYMV after aphid transmission were also tested for BYDV or other luteoviruses using broad-detection luteovirus primers Lu/L4 (Robertson et al. 1991). No luteovirus sequence amplification was observed in any of these samples (data not shown). Lyophilized tissue was used for vascular puncture inoculation (VPI) to CML541, Early Sunglow, Oh28, and Silver Queen maize using protocols previously described (Louie 1995). VPI is a wellestablished method for transmission of viruses to maize (for examples, see Benavente et al. 2012; Edwards et al. 2015; Redinbaugh 2003; Redinbaugh et al. 2001; Stewart et al. 2013; Weiland and Edwards 2011), especially valuable for viruses that are not rubtransmissible and for which vector(s) have not yet been identified or colonized. Inoculated plants were tested for presence of MaYMV at 14 dpi using primers DM03 and DM04. Leaves from plants in which MaYMV was detected were stored at $-80 \mathrm{C}$ and used for subsequent VPI to maize. Whether from lyophilized tissue from Tanzania or fresh or frozen newly infected material, VPI transmission rates did not exceed $\sim 6 \%$ (Table 2).

Aphid transmission and transmission rates were tested using each of two aphid colonies: $R$. maidis from a colony developed from

Table 1. Primers used for screening maize yellow mosaic virus (MaYMV), maize chlorotic mottle virus (MCMV), and sugarcane mosaic virus (SCMV) on aphid-infested plants

\begin{tabular}{lllcc}
\hline ID & Target virus & \multicolumn{1}{c}{ Sequences $\left(\mathbf{5}^{\prime} \ldots \mathbf{3}^{\prime}\right)$} & Size $(\mathbf{b p})$ & Target genomic region \\
\hline DM03 & MaYMV:1944F & GGGAGGTTACTTGCAGAGGG & 892 & RNA-dependent RNA polymerase (RdRp) \\
DM04 & MaYMV:2836R & ATGCACTTCAACCAACACGC & & RNA-dependent RNA polymerase (RdRp) \\
DM60 & MCMV:22F & GCGCTAGACACGACCTTACA & 1,676 & Capsid protein (CP) \\
DM66 & MCMV:1698R & CCACTAATTGGCTCAGGGCA & & \\
DM74 & SCMV:7874F & GGTGATGACCTGCTCCTAGC & 1,714 & \\
DM75 & SCMV:9588R & TCGCAACACAAGTGGCAAAG & & \\
\hline
\end{tabular}

Table 2. Vascular puncture transmission of maize yellow mosaic virus (MaYMV)

\begin{tabular}{|c|c|c|c|c|c|c|c|c|c|c|}
\hline \multirow{2}{*}{$\begin{array}{l}\text { Experiment \# } \\
\begin{array}{l}\text { Inoculum source } \\
\text { (sample \#) }\end{array}\end{array}$} & \multirow{2}{*}{$\begin{array}{c}\frac{1}{\text { Mixture: } \text { S15 }^{\mathrm{a}}} \\
\text { S18, } \mathrm{S} 19\end{array}$} & \multicolumn{2}{|c|}{2} & \multicolumn{2}{|c|}{3} & \multicolumn{2}{|c|}{4} & \multirow{2}{*}{$\frac{5}{\text { Exp. } 2 \text { aphid }_{\text {transmitted }}}$} & \multirow{2}{*}{ 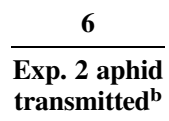 } & \multirow{2}{*}{$\begin{array}{c}\frac{7}{\text { Exp. } 2} \\
\text { VPI }\end{array}$} \\
\hline & & S20 & S30 & S20 & S30 & S20 & S30 & & & \\
\hline CML541 & $0 / 40$ & $0 / 40$ & $0 / 40$ & $\mathrm{NT}^{\mathrm{c}}$ & NT & NT & NT & NT & NT & NT \\
\hline Early Sunglow & $0 / 39$ & $0 / 39$ & $\begin{array}{c}1 / 39 \\
(2.5 \%)\end{array}$ & $0 / 39$ & $0 / 40$ & $0 / 39$ & $0 / 39$ & NT & NT & NT \\
\hline Oh28 & 0/39 & $0 / 38$ & $0 / 38$ & $0 / 37$ & $0 / 39$ & $0 / 39$ & $0 / 39$ & NT & NT & NT \\
\hline Silver Queen & $0 / 40$ & $0 / 38$ & $\begin{array}{c}1 / 40 \\
(2.5 \%)\end{array}$ & $0 / 40$ & $0 / 39$ & $0 / 40$ & $\begin{array}{c}1 / 39 \\
(2.5 \%)\end{array}$ & $\begin{array}{c}3 / 48 \\
(6.3 \%)\end{array}$ & $0 / 22$ & $\begin{array}{c}3 / 50 \\
(6.0 \%)\end{array}$ \\
\hline
\end{tabular}

\footnotetext{
a Sample 15 and plants inoculated with it were excluded from further study as it tested positive for potyvirus using an immunostrip assay.

${ }^{\mathrm{b}}$ For experiments 5 and 6, fresh VPI source tissue was derived from Early Sunglow plants to which aphids had transmitted virus recovered by VPI of lyophilized Tanzanian tissue in experiment \#2.

${ }^{c} \mathrm{NT}=$ not tested
} 
aphids collected in Kansas were kindly provided by A. Whitfield (NCSU), and reared on 'Early Sunglow' maize using established protocols; and Rhopalosiphum padi from a colony developed from insects collected in Wooster, Ohio, and similarly reared on 'Early Sunglow' maize. MaYMV was serially transmitted by aphids from infected plants recovered from VPI to Oh28 maize. Plants with infection confirmed by RT-PCR were used as a source of inoculum for aphid transmission tests to compare transmission by $R$. maidis and $R$. padi to Oh28 test plants. Inoculative aphids were prepared by infesting MaYMV-infected plants showing leaf reddening symptoms with first through third instar aphid nymphs. After a 7-day acquisition access period (AAP) on infected Oh28, five aphids, now adults, were transferred with a paint brush and caged on each test plant. Test plants were 7-day-old Oh28 seedlings (1 to 2 leaf stage), planted five per pot in eight to nine pots per treatment per replication. As a control, an equal number of seedlings were similarly caged with five nonviruliferous (unexposed) aphids per plant. Aphids were kept on test plants for 3 to 4 days (inoculation access period, IAP), then fumigated with dichlorvos (Nuvan Prostrips, AMVAC Chemical Corp., Newport Beach, CA) and placed to develop symptoms in a contained growth chamber at $25^{\circ} \mathrm{C}$ with $15 \mathrm{~h}$ light $/ 9 \mathrm{~h}$ dark.

After aphid transmission tests, symptoms were scored at $21 \mathrm{dpi}$. Many Oh28 plants showed leaf tip reddening (Fig. 1), which always corresponded with detection of MaYMV by RT-PCR. Plants without leaf reddening were also sampled and tested by RT-PCR using primers DM03 and DM04 in pools by pot, and again individually if pools were positive. The total number of plants infected post-transmission with symptoms or by RT-PCR were tabulated to determine total transmission rates (Table 3 ). R. maidis showed a mean transmission rate of $87.25 \%( \pm 0.22 \mathrm{SD})$ for five inoculative aphids/plant across three replicates, with $100 \%$ transmission in the second of two experimental replicates (Table 3). Under similar conditions, $R$. pad $i$ was significantly less efficient at virus transmission, with a mean transmission rate of $42.90 \%$ ( \pm 0.10 SD) across replicates. Similar percentages of plants in which virus was detected showed the characteristic reddening symptom (74\% and $73 \%$ for $R$. maidis and $R$. padi, respectively) at $21 \mathrm{dpi}$. Infected plants that did not show reddening symptoms at $21 \mathrm{dpi}$ eventually became red (data not shown), suggesting that establishment of infection or a threshold titer in these plants may have been delayed compared with plants showing earlier symptoms.

Several other maize genotypes also showed characteristic leaf reddening upon infection with MaYMV including Early Sunglow, Silver Queen, and Wf9xOh51 (Fig. 1C-E), but comprehensive symptom analyses by genotype have not yet been completed. Response variation based on host genotype for wheat flag leaf reddening or yellowing is well known for barley yellow dwarf viruses (BYDV) and cereal yellow dwarf viruses (CYDV) (reviewed in Nega 2014) and is thus important to further explore for MaYMV. Although symptoms were not comprehensively scored in plants with MaYMV transmission in Tanzania (some of which retained residual potyvirus), reddening was not observed by $28 \mathrm{dpi}$ in the white-kerneled PAN4M-19 hybrid. Interestingly, leaf textural changes (smoothness) were noted in infected but not uninfected Early Sunglow plants. Other,
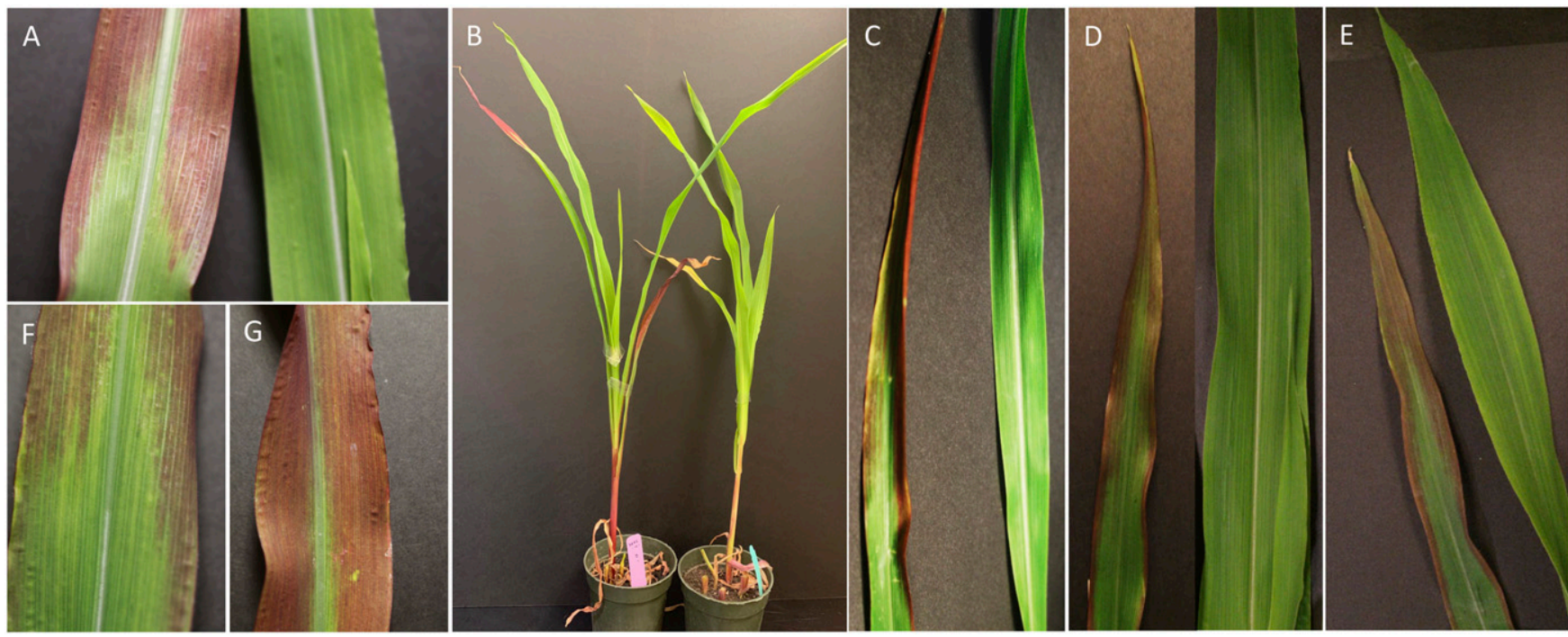

Fig. 1. Leaf reddening symptoms of maize yellow mosaic virus/maize yellow dwarf virus RMV2 in maize. A and B show comparisons of infected (left) and uninfected Oh28 plants, inoculated with viruliferous and nonviruliferous aphids, respectively, at 14 days post-aphid infestation (dpi). C compares Early Sunglow infected (left) and uninfected (right) leaves at $21 \mathrm{dpi}$; D compares Silver Queen infected (left) and uninfected (right) leaves at $16 \mathrm{dpi}$, and E compares Wf9x Oh51A infected (left) and uninfected (right) leaves at $21 \mathrm{dpi}$. F and G show leaf reddening in two leaves from other infected Oh28 plants at 14 dpi.

Table 3. Aphid transmission of maize yellow mosaic virus (MaYMV)

\begin{tabular}{|c|c|c|c|c|}
\hline Replicate & Aphid species & $\begin{array}{l}\text { MaYMV RT-PCR positive/total } \\
\text { nonviruliferous aphid treated plants }\end{array}$ & $\begin{array}{c}\text { MaYMV positive/total viruliferous } \\
\text { aphid treated plants }\end{array}$ & $\begin{array}{l}\text { Plants with } 21 \mathrm{dpi}^{\mathrm{b}} \text { leaf } \\
\text { reddening/total infected }\end{array}$ \\
\hline $388 \mathrm{a}-1$ & R. maidis & $0 / 35$ & $21 / 34(62 \%)$ & $12 / 21(57 \%)$ \\
\hline $388 \mathrm{a}-2$ & & $0 / 35$ & $31 / 31(100 \%)$ & $25 / 31(81 \%)$ \\
\hline $388 a-3$ & & $0 / 31$ & $34 / 34(100 \%)$ & $29 / 34(85 \%)$ \\
\hline Total & & 0/101 (0\%) & $86 / 99(87 \%)$ & $66 / 89(74 \%)$ \\
\hline $388 b-2$ & R. padi & $0 / 33$ & $18 / 35$ & $14 / 18(78 \%)$ \\
\hline $388 b-3$ & & $0 / 32$ & $15 / 35$ & $10 / 15(67 \%)$ \\
\hline $388 b-4$ & & $0 / 29$ & $11 / 35$ & $8 / 11(73 \%)$ \\
\hline Total & & $0 / 94(0 \%)$ & $44 / 105(42 \%)$ & $32 / 44(73 \%)$ \\
\hline
\end{tabular}

a All plants per pot pooled and tested by RT-PCR for MaYMV (primers DM03/DM04) and scored for symptoms at 21 dpi. No MaYMV or reddening was detected in any plants treated with naïve aphids.

b $\mathrm{dpi}=$ days post-aphid infestation. 
perhaps more subtle symptoms may remain to be described in detail, as do comprehensive host range, and yield impact of MaYMV.

Maize-feeding aphids are ubiquitous worldwide, as are the potyviruses they transmit. SCMV is prevalent, widely distributed, and very diverse in East Africa and has been reported to be transmitted by $R$. maidis and $R$. padi most efficiently and is also transmitted by Schizaphis graminum (Sahi et al. 2003). Aphids specifically cataloged in cereals and other grasses in Kenya, near Tanzania where our isolate was collected, include all three of these species in addition to numerous others (Eastop 1955). Unsurprisingly, aphids collected in Tanzania were able to transmit both SCMV and MaYMV, although with different transmission dynamics as expected since SCMV, as other potyviruses, is transmitted in a nonpersistent manner whereas poleroviruses are persistently transmitted by their vectors. Coinoculation as well as sequential inoculation of both viruses by aphid vectors is likely. SCMV and other potyviruses are endemic in locations where MLN has emerged, and MaYMV is also common in Tanzania in locations where MLN has not yet emerged, such as Morogoro (Massawe et al. 2018; data not shown). This fact and the shared vectors of MaYMV with SCMV suggests that despite its frequent codiscovery with MLN viruses, its presence probably predated MCMV emergence driving MLN. However, polerovirus infection in maize is easily overlooked due to symptoms that mimic nutrient deficiency or are virtually asymptomatic even when infected, probably dependent on both stage of infection progression and the maize genotype, with potential influence by environmental factors.

Our results elucidate fundamental biological characteristics of a recently discovered polerovirus that were previously confounded by coinfection in maize. Definition of symptoms (and lack thereof in some infected plants) as well as demonstration of two aphid vectors provides foundational knowledge from which to further characterize and assess the impact of this virus in maize. Like luteoviruses and other poleroviruses with similar transmission and biological characteristics such as BYDV and CYDV, MaYMV may have important plant health and yield impacts even in plants in which symptoms are not apparent or easily overlooked.

\section{Literature Cited}

Asiimwe, T., Stewart, L. R., Willie, K., Massawe, D., Kamatenesi, J., and Redinbaugh, M. G. 2020. Maize lethal necrosis (MLN) viruses and other maize viruses in Rwanda. Plant Pathol. https://doi.org/10.1111/ppa.13134

Benavente, L. M., Ding, X. S., Redinbaugh, M. G., Nelson, R. S., and Balint-Kurti, P. 2012. Virus-induced gene silencing in diverse maize lines using the brome mosaic virus-based silencing vector. Maydica 57:206-214.

Bernreiter, L., Teijeiro, R. G., Jarrin, D., Garrindo, P., and Ramos, L. 2017. First report of maize yellow mosaic virus infecting maize in Ecuador. New Dis. Rep. $36: 11$.
Chen, S., Jiang, G., Wu, J., Liu, Y., Qian, Y., and Zhou, X. 2016. Characterization of a novel polerovirus infecting maize in China. Viruses 8:120.

Eastop, V. F. 1955. Notes on East African aphids. VII. Grass and ceral stem- and leaf-feeding species. East Afr. Agric. J. 20:209-212.

Edwards, M. C., Weiland, J. J., Todd, J., and Stewart, L. R. 2015. Infectious maize rayado fino virus from cloned cDNA. Phytopathology 105:833-839.

Ghosh, S., Kanakala, S., Lebedev, G., Kontsedalov, S., Silverman, D., Alon, T. Mor, N., Sela, N., Luria, N., Dombrovsky, A., Mawassi, M., Haviv, S., Czosnek, H., and Ghanim, M. 2019. Transmission of a new polerovirus infecting pepper by the whitefly Bemisia tabaci. J. Virol. 93:e00488-19.

Gonçalves, M. C., Godinho, M., Alves-Freitas, D. M. T., Varsani, A., and Ribeiro, S. G. 2017. First report of maize yellow mosaic virus infecting maize in Brazil Plant Dis. 101:2156-2157.

Grisham, M. P., Johnson, R. M., and Zimba, P. V. 2010. Detecting Sugarcane yellow leaf virus infection in asymptomatic leaves with hyperspectral remote sensing and associated leaf pigment changes. J. Virol. Methods 167:140-145.

Guadie, D., Abraham, A., Tesfaye, K., Winter, S., Menzel, W., and Knierim, D. 2018. First report of maize yellow mosaic virus infecting maize (Zea mays) in Ethiopia. Plant Dis. 102:1044.

Louie, R. 1995. Vascular puncture of maize kernels for the mechanical transmission of maize whilte line mosaic virus and other viruses of maize. Phytopathology 85:139-143.

Mahuku, G., Lockhart, B. E., Wanjala, B., Jones, M. W., Kimunye, J. N., Stewart, L. R., Cassone, B. J., Sevgan, S., Nyasani, J. O., Kusia, E., Kumar, P. L., Niblett, C. L., Kiggundu, A., Asea, G., Pappu, H. R., Wangai, A., Prasanna, B. M., and Redinbaugh, M. G. 2015. Maize lethal necrosis (MLN), an emerging threat to maize-based food security in sub-Saharan Africa. Phytopathology 105:956-965.

Massawe, D. P., Stewart, L. R., Kamatenesi, J., Asiimwe, T., and Redinbaugh, M. G. 2018. Complete sequence and diversity of a maize-associated Polerovirus in East Africa. Virus Genes 54:432-437.

Nega, A. 2014. Review on Barley yellow dwarf virus. J. Biol. Agric. Healthc. 4(27):33-54.

Palanga, E., Longue, R. D. S., Koala, M., Neya, J. B., Traore, O., Martin, D. P., Peterschmitt, M., Filloux, D., and Roumagnac, P. 2017. First report of maize yellow mosaic virus infecting maize in Burkina Faso. New Dis. Rep. 35:26.

Redinbaugh, M. G. 2003. Transmission of Maize streak virus by vascular puncture inoculation with unit-length genomic DNA. J. Virol. Methods 109:95-98.

Redinbaugh, M. G., Louie, R., Ngwira, P., Edema, R., Gordon, D. T., and Bisaro, D. M. 2001. Transmission of viral RNA and DNA to maize kernels by vascular puncture inoculation. J. Virol. Methods 98:135-143.

Robertson, N. L., French, R., and Gray, S. M. 1991. Use of group-specific primers and the polymerase chain reaction for the detection and identification of luteoviruses. J. Gen. Virol. 72:1473-1477.

Sahi, M., Wakil, G. M., and Imanat, Y. 2003. Aphid transmission of sugarcane mosaic virus (SCMV). Pak. J. Agric. Sci. 40:74-76.

Stewart, L. R., Paul, P. A., Qu, F., Redinbaugh, M. G., Miao, H., Todd, J., and Jones, M. 2013. Wheat mosaic virus (WMoV), the causal agent of high plains disease, is present in Ohio wheat fields. Plant Dis. 97:1125-1125.

Wang, F., Zhou, B. G., Gao, Z. L., and Xu, D. F. 2016. A new species of the genus Polerovirus causing symptoms similar to maize yellow dwarf virus-RMV of maize in China. Plant Dis. 100:1508.

Weiland, J. J., and Edwards, M. C. 2011. Linear-motion tattoo machine and prefabricated needle sets for the delivery of plant viruses by vascular puncture inoculation. Eur. J. Plant Pathol. 131:553-558. 